\title{
Mapping rainfall erosivity at a regional scale: a comparison of interpolation methods in the Ebro Basin (NE Spain)
}

\author{
M. Angulo-Martínez ${ }^{1}$, M. López-Vicente ${ }^{3}$, S. M. Vicente-Serrano ${ }^{2}$, and S. Beguería ${ }^{1}$ \\ ${ }^{1}$ Department of Soil and Water, Aula Dei Experimental Station - CSIC, 1005 Avda. Montañana, 50080-Zaragoza, Spain \\ ${ }^{2}$ Department of Geo-environmental Processes and Global Change, Pyrenean Institute of Ecology - CSIC, 1005 \\ Avda. Montañana, 50080-Zaragoza, Spain \\ ${ }^{3}$ Department of Earth and Environmental Sciences, Katholieke Universiteit Leuven, Celestijnenlaan 200E, 3001 \\ Leuven-Heverlee, Belgium
}

Received: 25 November 2008 - Published in Hydrol. Earth Syst. Sci. Discuss.: 19 January 2009

Revised: 17 July 2009 - Accepted: 7 September 2009 - Published: 19 October 2009

\begin{abstract}
Rainfall erosivity is a major causal factor of soil erosion, and it is included in many prediction models. Maps of rainfall erosivity indices are required for assessing soil erosion at the regional scale. In this study a comparison is made between several techniques for mapping the rainfall erosivity indices: i) the RUSLE R factor and ii) the average $\mathrm{EI}_{30}$ index of the erosive events over the Ebro basin (NE Spain). A spatially dense precipitation data base with a high temporal resolution (15 min) was used. Global, local and geostatistical interpolation techniques were employed to produce maps of the rainfall erosivity indices, as well as mixed methods. To determine the reliability of the maps several goodness-of-fit and error statistics were computed, using a cross-validation scheme, as well as the uncertainty of the predictions, modeled by Gaussian geostatistical simulation. All methods were able to capture the general spatial pattern of both erosivity indices. The semivariogram analysis revealed that spatial autocorrelation only affected at distances of $\sim 15 \mathrm{~km}$ around the observatories. Therefore, local interpolation techniques tended to be better overall considering the validation statistics. All models showed high uncertainty, caused by the high variability of rainfall erosivity indices both in time and space, what stresses the importance of having long data series with a dense spatial coverage.
\end{abstract}

\section{Introduction}

Soil erosion has become a major environmental threat due to the growth of the World's population, and is one of the main consequences of projected land use and climate change sce-

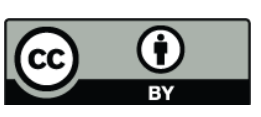

Correspondence to:

M. Angulo-Martínez

(mangulo@eead.csic.es) narios (Gobin et al., 2004). Studies on soil erosion started in the first decades of the 20th Century, and have increased in number and variety since then. Isolating the role of different natural and management factors on soil erosion has been one of the major research topics. The combination of those factors in the form of a parametric model allowed the development of tools such as the USLE (Wischmeier and Smith, 1978; Kinnell and Risse, 1998), which can be used for predicting the effect of different management strategies on soil erosion rates. The development of parametric models opened a new area of research, devoted to analyze the spatial variability of erosion causal factors. Maps showing the spatial distribution of natural and management related erosion factors are of great value in the early stages of land management plans, allowing identify preferential areas where action against soil erosion is more urgent or where the remediation effort will have highest revenue. With the advent of Geographic Information Systems (GIS), studies of this kind have become more and more frequent.

Among the natural factors affecting soil erosion, rainfall erosivity has a paramount importance. Precipitation is a major cause of soil erosion, given the extraordinary importance of soil detachment processes due to drop impact and runoff shear. Compared to other natural factors such as the relief or the soil characteristics, rainfall erosivity has very little or null possibility of modification by humans, so it represents a natural environmental constrain that limits and conditions land use and management. In the context of climate change, the effect of altered rainfall characteristics on soil erosion is one of the main concerns of soil conservation studies.

It is well known that a few, very intense rainfall events are responsible for the largest part of the soil erosion and sediment delivery (González-Hidalgo et al., 2007). Hence, the estimation of rainfall erosivity may contribute to a better prediction of soil erosion. Rainfall erosivity can be quan-

Published by Copernicus Publications on behalf of the European Geosciences Union. 
tified by several erosivity indices which evaluate the relationship between drop size distribution and kinetic energy of a given storm. Numerous works have assessed the role of drop size distribution of both natural and simulated rainfall at the field plot scale on soil detachment. These measurements are difficult to perform, and because of that they are very rare both in space and time. In addition, natural rainfall properties measurements are scarce for comparisons with simulated rain (Dunkerley, 2008). This has motivated researchers to undertake studies relating more conventional rainfall characteristics such as the maximum intensity during a period of time to rainfall energy or directly to soil detachment rates. Examples of such indices of rainfall erosivity are the USLE R factor, which summarizes all the erosive events quantified by the $\mathrm{EI}_{30}$ index occurred along the year (Wischmeier, 1959; Wischmeier and Smith, 1978; Brown and Foster, 1987; Renard and Freimund, 1994; Renard et al., 1997), the modified Fournier index for Morocco (Arnoldus, 1977), the KE $>25$ index for southern Africa (Hudson, 1971) and the AIm index for Nigeria (Lal, 1976).

Mapping rainfall erosivity at regional and basin scale is still an emerging research question. Such maps allow for a better comprehension of the processes with geographical imprint as well as the application of these methodologies to large spatial areas. They are also an important step for large-scale soil erosion assessments, soil conservation management of natural resources, agronomy and agrochemical exposure risk assessments (Winchell et al., 2008). Early examples are the rainfall erosivity maps for the whole USA in the form of isoerodent maps or maps of the RUSLE R factor (Renard and Freimund, 1994). Other researchers have used regression techniques to elaborate spatially continuous maps of rainfall erosivity on the basis of other available data such as daily and monthly records of rainfall depth (ICONA, 1988).

With the advent of GIS packages and the generalization of spatial interpolation techniques, maps of environmental parameters such as those relevant for soil erosion have become frequent. For example, several authors have used GIS 'techniques to map the factors of the RUSLE equation by means of interpolation methods (Shi, 2004; Lim, 2005; Mutua, 2006; López-Vicente et al., 2008). There are a number of statistical methods available, such as regression models; local interpolators such as the inverse distance weighting (IDW) or thin-plate splines, or geostatistical techniques such as kriging (Burrough and McDonnell, 1998). Recent studies, mostly in the field of Climatology (e.g., Ninyerola and Pons, 2000; Vicente-Serrano et al., 2003; Beguería and VicenteSerrano, 2006), highlighted the interest of finding the method with the best adjustment to the observed data.

There are few studies comparing among interpolation techniques for rainfall erosivity indices. Millward (1999) calculated the $\mathrm{EI}_{30}$ index at the monthly scale and the $\mathrm{R}$ factor with geostatistics and IDW techniques for the Algarve region (Southern Portugal). Hoyos (2005) observed that a local polynomial algorithm gave lower mean prediction errors than the IDW in the Colombian Andes. Goovaerts (1999) discussed the relation between rainfall erosivity and elevation in the comparison of three different geostatistical methods. None of these works provided a comprehensive comparison of mapping methods at the regional scale.

This work aims at comparing different interpolation methods to map the average $\mathrm{EI}_{30}$ index of the erosive events and the RUSLE R factor in a large and climatologically complex area: the Ebro basin, in North-Eastern Spain. Results of rainfall erosivity cartography can be used as a reference for soil protection practices and discussion of the different interpolation methods will be of interest to enhance regional and basin cartography.

\section{Materials and methods}

\subsection{Study area}

The study area covers the north-east of Spain (Fig. 1). It corresponds to the Ebro Basin, which represents an area of about $85000 \mathrm{~km}^{2}$. The Ebro valley is an inner depression surrounded by high mountain ranges. It is limited to the North by the Cantabrian Range and the Pyrenees, with maximum elevations above $3000 \mathrm{~m}$ a.s.l. The Iberian range closes the Ebro valley to the South, with maximum elevations in the range of the 2000-2300 m. To the East, parallel to the Mediterranean coast, the Catalan Coastal Range closes the Ebro valley, with maximum elevations between 1000 and $1200 \mathrm{~m}$ a.s.l.

The climate is influenced by the Cantabric and Mediterranean Seas and the effect of the relief on precipitation and temperature. The border mountain ranges isolate the central valley blocking the maritime influence, resulting in a continental climate which experiments aridity conditions (Cuadrat, 1991; Lana and Burgueño, 1998; Creus 2001; Vicente-Serrano 2005). A climatic gradient in the NW-SE direction is remarkable, determined by the strong Atlantic influences in the north and north-west of the area during large part of the year and the Mediterranean influence to the east. Mountain ranges add complexity to the climate of the region. The Pyrenees extend the Atlantic influence to the east by increasing precipitation, whereas the Cantabrian Range, which runs parallel to the Atlantic coastland in the NW, is a barrier to the humid flows and has a noticeable climate contrast between the north (humid) and the south (dry) slopes.

The precipitation regime shows strong seasonality (Garrido and García, 1992), which involves not only the amount of precipitation but also its physical cause (frontal or convective). Precipitation in the inland areas is characterised by alternating wet and dry periods as a consequence of the seasonal displacement of the polar front and its associated pressure systems. Inter-annual variability of precipitation can be very high, and drought years can be followed by torrential rain events which last for many days (Martín-Vide, 1994). 


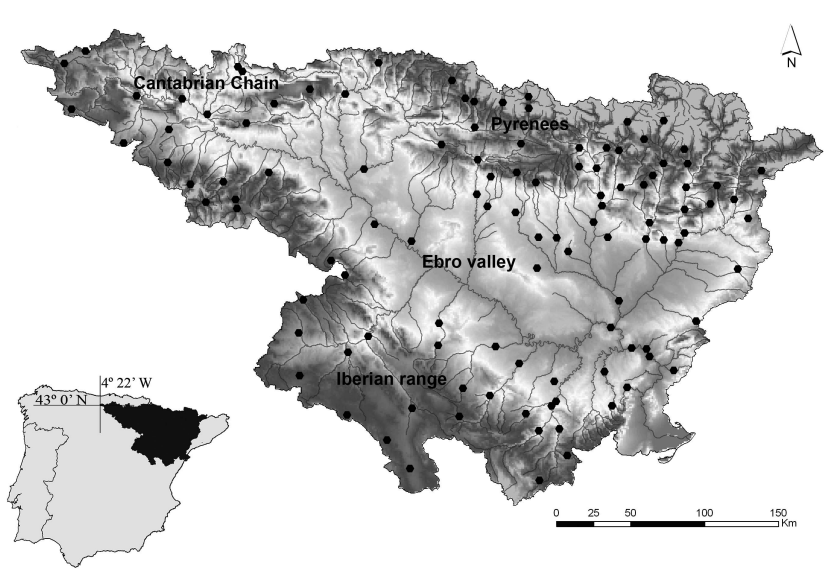

Fig. 1. Location of the study area and the observatories used on this study.

Close to the Mediterranean Sea the precipitation amount also increases as a consequence of the maritime influence. Nevertheless, the precipitation frequency, intensity and seasonality are very different compared to the areas in the North, where precipitation is frequent but rarely very intense, with the exception of mountainous areas (García-Ruiz et al., 2000). The most extreme precipitation events are recorded along the Mediterranean seaside (Llasat, 2001; Romero et al., 1998; Peñarrocha et al., 2002). The Ebro Basin has a long record of social, economic and environmental damages caused by extreme rainfall events (García-Ruiz et al., 2000; Lasanta, 2003) due to its complex climatology, as a meteorological border region, and the contrasted relief.

\subsection{Data base}

The database consisted on 112 selected rainfall series from the Ebro Hydrographical Confederation SAIH system - Automatic Hydrological Information Network (Fig. 1). Each station provides precipitation data at a time resolution of $15 \mathrm{~min}$. The system started in 1997, and is the only dense network providing sub-daily resolution data in the region. We used all available series data for the period 1 January 1997 to 31 December 2006.

The rainfall series were subjected to a quality control that allowed identifying wrong records due to system failures. These records were replaced by the corresponding ones from a nearby station. This allowed creating an erosive events database (EEDB). The erosive events were determined by the RUSLE criterion: an event is considered erosive if at least one of this conditions is true: i) the cumulative rainfall is greater than $12.7 \mathrm{~mm}$, or ii) the cumulative rainfall has at least one peak greater than $6.35 \mathrm{~mm}$ in $15 \mathrm{~min}$. Two consecutive events are considered different from each other if the cumulative rainfall in a period of $6 \mathrm{~h}$ is greater than $1.27 \mathrm{~mm}$.

\subsection{Rainfall erosivity index}

The rainfall erosivity indices employed were the average $\mathrm{EI}_{30}$ index events and the RUSLE $\mathrm{R}$ factor. These indices have been widely used, making it possible to compare the results with those of other studies. The RUSLE model uses the Brown and Foster (1987) approach for calculating the average annual rainfall erosivity, $R\left(\mathrm{MJ} \mathrm{mm} \mathrm{ha}{ }^{-1} \mathrm{~h}^{-1} \mathrm{y}^{-1}\right)$ :

$R=\frac{1}{n} \sum_{j=1}^{n} \sum_{k=1}^{m_{j}}\left(\mathrm{EI}_{30}\right)_{k}$

where $n$ is the number of years of records, $m_{j}$ is the number of erosive events of a given year $j$, and $\mathrm{EI}_{30}$ is the rainfall erosivity index of a singular event $k$. Thus, the $\mathrm{R}$ factor is the average value of the annual cumulative $\mathrm{EI}_{30}$ over a given period. The event's rainfall erosivity $\mathrm{EI}_{30}\left(\mathrm{MJ} \mathrm{mm} \mathrm{ha}^{-1} \mathrm{~h}^{-1}\right)$ is obtained as follows:

$\mathrm{EI}=\mathrm{EI}_{30}=\left(\sum_{r=1}^{o} e_{r} v_{r}\right) I_{30}$

where $e_{r}$ and $v_{r}$ are, respectively, the unit rainfall energy $\left(\mathrm{MJ} \mathrm{ha}^{-1} \mathrm{~mm}^{-1}\right.$ ) and the rainfall volume $(\mathrm{mm})$ during a time period $r$, and $I_{30}$ is the maximum rainfall intensity during a period of $30 \mathrm{~min}$ in the event $\left(\mathrm{mm} \mathrm{h}^{-1}\right)$. The unit rainfall energy, $e_{r}$, is calculated for each time interval as:

$e_{r}=0.29\left[1-0.72 \exp \left(-0.05 i_{r}\right)\right]$

where $i_{r}$ is the rainfall intensity during the time interval $\left(\mathrm{mm} \mathrm{h}^{-1}\right)$. In addition to the $\mathrm{R}$ factor, we also calculated the average $\mathrm{EI}_{30}$ of the erosive events over the study period.

The average $\mathrm{EI}_{30}$, is calculated as the mean erosivity of all rainfall events. Since the frequency distribution of $\mathrm{EI}_{30}$ is highly skewed (it follows a logarithmic law), the average $\mathrm{EI}_{30}$ is in fact most correlated with the highest erosive events. Maps showing the spatial distribution of the average $\mathrm{EI}_{30}$ index complement the information given by the $\mathrm{R}$ factor alone.

\subsection{Spatial modelling}

In many studies the rainfall erosivity calculation is reduced to at-site analysis. An improvement focus on the reduction of the risk of erosion in landscape management and conservation planning is to obtain continuous maps for large areas as a preliminary step to evaluate the hazard. For this purpose a common procedure is the mapping of at-site estimated rainfall erosivity index values by means of interpolation techniques (e.g., Prudhome and Reed, 1999; Weisse and Bois, 2002).

In this article several interpolation methods including global, local and mixed approaches, are compared in order to determine which one describes better the spatial distribution of the average $\mathrm{EI}_{30}$ index and the $\mathrm{R}$ factor. A leave-one-out cross-validation technique was used for validating the goodness of fit (Efron and Tibshirani, 1997). 
For the regression-based models, a digital elevation model (DEM) and a digital coverage of the Iberian Peninsula coastline were used. Both were obtained from the Ebro Hydrographical Confederation (http://www.chebro.es/).

\subsubsection{Global methods}

The global method used was generalized least squares (GLS) multiple regression. Regression is a global approach to spatial interpolation, and it is based on finding empirical relationships between the variable of interest and other spatial variables. Regression-based techniques adapt to almost any space and usually generate adequate maps (Goodale et al., 1998; Vogt et al., 1997; Ninyerola et al., 2000). The relationships between climatic data and topographic and geographic variables have been extensively analyzed throughout the scientific literature, and regression-based models allow exploiting this relationship to produce maps of the climatic parameters. Some authors have shown the advantages of incorporating the information provided by ancillary data on mapping extreme rainfall probabilities (Beguería and Vicente-Serrano, 2006; Casas et al., 2007). Regression methods can be especially adequate in large regions with complex atmospheric influences, such as the Ebro Valley (Daly et al., 2002; Weisse and Bois, 2002; Vicente-Serrano et al., 2003), or if the sample network is not dense enough for local interpolation methods (Dirks et al., 1998).

GLS is an extension of the most common ordinary least squares (OLS) regression, which allows for autocorrelation in the dependent variable (Cressie, 1993). When dealing with spatial variables, it is common assumption that the observations are autocorrelated; this property forms, in fact, the basis of all geostatistical and mixed methods. The existence of autocorrelation in the residuals violates one of the main assumptions of OLS, thus making this technique not suitable for climatic variables with geographical imprint. This problem can be easily solved by using alternative regression techniques that account explicitly for spatial autocorrelation, such as GLS (Beguería and Pueyo, 2009). The differences between both methods can be easily explained by introducing their mathematical background. From the common OLS formula:

$y=X \beta+\varepsilon$

where $y$ is the dependent variable, $\mathbf{X}$ is a matrix of $p$ independent variables (model matrix), $\boldsymbol{\beta}$ is a vector of $p+1$ model coefficients to estimate, including a constant $\beta_{0}$, and $\varepsilon$ is a vector of random errors. In OLS it is assumed that the errors are normally distributed with mean 0 and variance $I$ : $\varepsilon \sim N\left(0, \sigma^{2} I\right)$. In GLS, on the contrary, it is generally assumed that $\varepsilon \sim N(0, \Sigma)$, where the error variance-covariance matrix $\Sigma$ is symmetric and positive-definite. Different diagonal entries in $\Sigma$ correspond to non-constant error variances, while nonzero off-diagonal entries correspond to correlated errors. Since the error variance-covariance matrix $\Sigma$ is not known, it must be estimated from the data along with the regression coefficients $\beta$. Due to the high number of elements of $\Sigma$, it needs to be approximated by a parametric model. In the case of spatial regression, $\Sigma$ can be adequately parameterized by a semi-variogram model. The semi-variogram model explains the covariance between the errors based on the distance between pairwise observations. Since the semivariogram constitutes the basis of geostatistical interpolation methods, it is explained in depth in a further section (see Sect. 2.4.3).

We used a set of independent variables at a spatial resolution of $100 \mathrm{~m}$. Elevation is usually the main determinant of the spatial distribution of climatic variables. Nevertheless, other variables such as the latitude and longitude, or the incoming solar radiation may also have an influence on the distribution of erosive rains. All variables were derived from a DEM (UTM-30N coordinates). The incoming solar radiation is a spatially continuous variable that depends on the terrain aspect (northern and southern slopes have low and high incoming solar radiation values, respectively). The annual mean incoming solar radiation was calculated following the algorithm of Pons and Ninyerola (2008). All these variables were processed in the MiraMon GIS package (Pons, 2006). Low-pass filters with radii of 5, 10 and $25 \mathrm{~km}$ were applied to elevation, slope and incoming solar radiation in order to measure the widest influence of these variables.

We used a Gaussian semivariogram model to parameterize the spatial autocorrelation between regression errors. As independent variables we used the spatial coordinates (longitude and latitude) in $\mathrm{km}$ and their squares $\left(\mathrm{km}^{2}\right)$, the elevation ( $\mathrm{m}$ a.s.l.), and the incoming solar radiation $\left(\mathrm{J} \mathrm{d}^{-1}\right)$. The $\mathrm{R}$ statistical analysis package (R Development Core Team, 2008) was used for the regression analysis.

\subsubsection{Local methods}

In global methods, local variations are dismissed as random, unstructured noise, and the climatic map is created on the basis of general structure of the variable at all available points (Borrough and McDonnell, 1998). Local methods, on the contrary, use only the data of the nearest sampling points for climatic mapping. Since interpolated values at ungauged locations depend on the observed values, local methods strongly depend on a sufficiently dense and evenly spaced sampling network.

Two local methods were used: inverse distance weighting (IDW) and splines. The IDW interpolation is based on the assumption that the climatic value at an unsampled point $z(x)$ is a distance-weighting average of the climatic values at nearby sampling points $z\left(x_{1}\right), z\left(x_{2}\right), \ldots, z\left(x_{n}\right)$. Climatic values are more similar at closer distances, so the inverse distance $\left(1 / d_{i}\right)$ between $z\left(x_{i}\right)$ and $z(x)$ is used as the weighting 
factor:

$$
z(x)=\frac{\sum_{i=1}^{n} z\left(x_{i}\right) d_{i j}^{-r}}{\sum_{i=1}^{n} d_{i j}^{-r}}
$$

where $z(x)$ is the predicted value, $z\left(x_{i}\right)$ is the climatic value at a neighbouring weather station, $d_{i j}$ is the distance between $z(x)$ and $z\left(x_{i}\right)$, and $r$ is an empirical parameter. Models with $r=1, r=2$ and $r=3$ were tested.

The splines method is based on a family of continuous, regular and derivable functions. Splines are similar to the equations obtained from the trend surfaces or regressionbased methods, but they are fitted locally from the neighbouring points around the candidate location $x$. A new function is created for each location $x$, without lost of continuity properties among the curves. Smoothing or tension parameters can be specified, resulting in more or less smoothed maps. The predicted value $z(x)$ is determined by two terms:

$z(x)=T(x)+\sum_{i=1}^{n} \lambda_{j} \psi_{j}\left(r_{i}\right)$

where $T(x)$ is a polynomial smoothing term, and the second term groups a series of radial functions where $\psi_{j}\left(r_{i}\right)$ is a known group of functions, and $\lambda_{j}$ represents the parameters (Mitasova et al., 1995):

$\psi\left(r_{i}\right)=-\left[\ln \left(\frac{\varphi r_{i}}{2}\right)+E_{i}\left(\frac{\varphi r_{i}}{2}\right)+C_{E}\right]$

where $\phi$ is the tension coefficient, $C_{E}=0.577215 \ldots$ is the Euler constant, $E_{i}$ is the exponential integral function, and $r_{i}$ is:

$r_{i}=\sqrt{\left(x-x_{i}\right)^{2}+\left(y-y_{i}\right)^{2}}$

The algorithms for fitting splines are quite complex but are currently standard in GIS packages. In this paper several spline interpolations were used as implemented in the ArcGIS 9.3 software. Tension and smoothing parameters were $\phi=400, \phi=5000, T(x)=0$ and $T(x)=400$.

\subsubsection{Geostatistical interpolation methods}

Kriging methods assume that the spatial variation of a continuous climatic variable is too irregular to be modelled by a continuous mathematical function, and its spatial variation could be better predicted by a probabilistic surface. This continuous variable is called a regionalized variable, which consists of a drift component and a random, spatially correlated component (Burrough and McDonnell, 1998). Hence, the spatially located climatic variable $z(x)$ is expressed by:

$z(x)=m(x)+\varepsilon^{\prime}(x)+\varepsilon^{\prime \prime}$

where $m(x)$ is the drift component, i.e. the structural variation of the climatic variable, $\varepsilon^{\prime}(x)$ are the spatially correlated residuals, i.e. the difference between the drift component and the sampling data values, and $\varepsilon^{\prime \prime}$ are spatially independent residuals. The predictions of kriging-based methods are currently a weighted average of the data available at neighbouring sampling points (weather stations). The weighting is chosen so that the calculation is not biased and the variance is minimal. A function that relates the spatial variance of the variable is determined using a semi-variogram model which indicates the semivariance $(\gamma)$ between the climatic values at different spatial distances.

The semivariogram describes the way in which similar observation values are clustered in space, in accordance with Tobler's first law of geography (Tobler, 1970). The semivariogram is therefore a measure of the dissimilarity of data pairs as the spatial separation between them increases (Deutsch and Journel, 1998). The semivariance is calculated for lagged sets of separation vectors $h_{u}$ as half the mean squared pairwise difference between the $N$ observed values within the spatial lag, $u$ :

$\gamma_{u}\left(h_{u}\right)=\frac{1}{2 N\left(h_{u}\right)} \sum_{N\left(h_{u}\right)}\left[z(u)-z\left(u+h_{u}\right)\right]^{2}$

To summarize the autocorrelation in space, a product-sum covariance model was automatically fitted to the semivariogram. First, only the sample semivariograms, $\gamma_{s, t}\left(h_{s}, 0\right)$, were considered. Valid semivariogram models were fitted to them, estimating automatically the partial range $\left(\phi_{u}\right)$ and sill $\left(\operatorname{sill}_{u}\right)$ and adding a nugget discontinuity $\left(\tau_{u}\right)$ at the origin to reflect spatial uncertainty if required. Semivariogram models must be selected from a set of allowable functions that are conditionally negative definite (Mcbratney and Webster, 1986), i.e. spherical, exponential or gaussian models (Deutsch and Journel, 1998). There is some argument over the correct way to proceed in semivariogram model fitting (Diggle et al., 2002; Goovaerts, 1997); we favoured automatically fitting by the OLS method, followed by adjustment by eye, to reduce the effect of outliers. The Gaussian function adjusted best. Predictions may improve depending in the number of neighbours included in the interpolation. Our data were not very sensible to the number of neighbours. A combination of 9 neighbours, including at least 3 fitted best.

Several types of kriging methods have been proposed, depending on how the drift component $m(x)$ is modelled (see, e.g., the reviews by Isaaks and Strivastava, 1989; Goovaerts, 1997; Burrough and McDonnell, 1998). Simple kriging (SK) assumes a known constant trend (expected value), $m(x)=0$, and relies on a covariance function. However, neither the expectation nor the covariance function are usually known, so simple kriging is seldom used. In ordinary kriging $(\mathrm{OK})$, the most common type of kriging, an unknown constant trend is assumed, $m(x)=E(z(x))$, and the estimation relies on a semivariogram model which is estimated from the sample.

SK and OK both assume stationarity of the spatial field, i.e. that the expected value of the variable does not change 
in space. This is often not the case with climatic variables, which tend to show spatial trends due to differences in the exposure to the atmospheric factors. Universal kriging (UK) allows incorporating non-stationarity by assuming a general linear trend model,

$m(x)=\sum_{k=0}^{p} \beta_{k} f(x)$

where $p$ defines the order of the polinomial model on the spatial coordinates of the point, $f(x)$. This process is often called trend removal, and it is interesting because it can capture a real spatial structure present in the data. However, it increases the complexity of the kriging model by adding more parameters for estimation. A two-dimensional quadratic surface, for example, adds five parameters beyond the intercept parameter that need to be estimated. As it is well known, the more parameters to be estimated, the more uncertain the model becomes.

Spatial structure can also arise in climatic data due to covariation with other geographical factors such as the elevation or the solar incoming radiation. Co-kriging (CK) allows considering the influence of external variables (co-variates) by analysing the cross-correlation between the errors of the different variables, $\varepsilon_{1}^{\prime}(x), \varepsilon_{2}^{\prime}(x)$, etc.

Spatial correlation may occur at different distances when different directions are considered; this characteristic is called anisotropy. Since the Ebro basin has a marked NW-SE structure, the effect of including anisotropy in the model was also evaluated.

In our study we compared OK, UK and CK methods. The order of the trend removal component in UK was determined by the lowest root mean square error, computed by a leaveone-out bootstrap process. In the case of CK we used the elevation, as determined by a digital terrain model (DTM), as the spatially distributed co-variate; the kriging method used was the best one from the previous methods, i.e. OK and UK. All geostatistical analyses were done with the ArcGIS 9.3 software.

\subsubsection{Mixed methods}

Mixed methods, also called "hybrid" (Hengl et al., 2004), are based on a combination of regression and local interpolation techniques or kriging, exploiting the ability of regression to relate the target variable to other spatially distributed variables and the spatial self-correlation acting at the local scale on most spatial variables. Alternative forms of mixed methods have been proposed in the last years for mapping environmental variables (Odeh et al., 1994, 1995; Brown and Comrie, 2002; McBratney et al., 2003; Hengl et al., 2004; Ninyerola et al., 2007; Vicente-Serrano et al., 2007). These and other studies have demonstrated that mixed methods usually allow for more precise and detailed representations of the target variables.
There are several types of mixed interpolation methods which vary upon their procedure. When regression residuals $(\varepsilon)$ are interpolated by means of kriging two methods can be used: i) in kriging with external drift (KED), the drift component is defined by regression upon some auxiliary variables and fitted together with the spatial distribution of the residuals (Wackernagel, 1998; Chiles and Delfiner, 1999); ii) in regresion-kriging (RK) the drift and the residuals are fitted separately and then summed (Ahmed and Marsily, 1987; Odeh et al., 1994, 1995). Other kind of mixed methods interpolate residuals using local methods as the inverse distance weighting interpolation or splines (Vicente-Serrano et al., 2003; Ninyerola et al., 2007).

In this study we used RK. To avoid misconceptions or sub-optimal solutions (Hengl et al., 2004), regression predictions were calculated by means of GLS (see Sect. 2.4.1.), and then residuals surfaces were fitted by $\mathrm{OK}$ and added to the GLS predictions. The $\mathrm{R}$ statistical analysis package (R Development Core Team, 2008) was used for RK.

\subsection{Local uncertainty assessment}

Spatial modelling involves uncertainty associated to the continuous estimated surface. Estimating the standard error of the predictions is necessary for completing the spatial modelling. In the case of spatial variables the problem is more complex, since the standard error of the predictions is also a spatial variable (Goovaerts, 2001). In this study we have used the technique called Gaussian geostatistical simulation (GGS). GSS generates multiple, equally probable representations of the spatial distribution of the attribute under study. A normal score transformation is performed on the data so that it will follow a standard normal distribution (mean $=0$ and $\sigma^{2}=1$ ). Conditional simulations are then run on this normally distributed data, and the results are back-transformed to obtain simulated output in the original units. Given a high enough number of simulations, its average will tend to equal the surface estimated by SK. The standard deviation of the simulations is taken as an estimator of the standard error of the estimated surface, from which confidence bands can be constructed. These representations provide a way to measure uncertainty for the unsampled locations taken all together in space rather than one by one (as measured by the kriging variance). We performed a series of 1000 conditioned simulations from an initial SK model with second order trend removal. GGS was performed with the ArcGIS 9.3 software.

\subsection{Validation statistics}

The resulting maps were compared by using a set of validation statistics. A leave-one-out procedure was used, consisting in fitting the model $n-1$ times $-n$ being the number of observations in the data set, each time one observation is left out of the fitting sample. These observations are used to calculate the model residuals, i.e. the difference between the predicted 
Table 1. Computation of several goodness of fit statistics used on this study.

\begin{tabular}{ll}
\hline Statistical critera & Definitions: \\
\hline & $N$ : no. of observations \\
& $O$ : observed value \\
$\bar{O}:$ mean of obs. values & $P:$ predicted value \\
& $P_{i}^{\prime}=P_{i}^{-} \bar{O}$ \\
& $O_{i}^{\prime}=O_{i}^{-} \bar{O}$ \\
& $\mathrm{MBE}=N^{-1} \sum_{i=1}^{N}\left(P_{i}-O_{i}\right)$ \\
Mean bias error (MBE) & $\mathrm{MAE}=N^{-1} \sum_{i=1}^{N}\left|P_{i}-O_{i}\right|$ \\
Mean absolute error (MAE) & \\
Willmontt's $D$ & $D=1-\frac{\sum_{i=1}^{N}\left(P_{i}-O_{i}\right)^{2}}{\sum_{i=1}^{N}\left(\left|P_{i}^{\prime}\right|+\left|O_{i}^{\prime}\right|\right)^{2}}$ \\
\hline
\end{tabular}

and the observed values. Cross-validation techniques are preferred to more traditional split-sample procedures for estimating generalization error, since they allow an independent validation without sacrificing an important amount of data (Weiss and Kulikowski, 1991). Cross-validation is compulsory when comparing exact interpolators such as IDW or splines, which by definition give an exact value at the locations used for fitting the model, i.e. all residuals at these points are zero.

We used a set of goodness of fit statistics not to rely on a single one (Table 1). These include: i) the mean bias error (MBE), which is centred around zero and is an indicator of prediction bias; ii) the mean absolute error (MAE), which is a measure of the average error; and iii) the agreement index $D$ (Willmott, 1981), which scales the magnitude of the variables, retains mean information and does not amplify the outliers. We avoided using the root mean square error (RMSE) because it is highly biased by outlier observations, and also because it is difficult to discern whether it reflects the average error or the variability of the squared errors (Willmott and Matsuura, 2005).

\section{Results}

The spatial structure of the data was initially assessed by empirical semivariograms, (Fig. 2). Spatial autocorrelation was present for both variables at relatively short distances (less than $15 \mathrm{~km}$ ). Above this distance the spatial autocorrelation disappeared, as it was also visible in the fitted Gaussian semivariogram models.

All interpolation methods were able to capture the regional distribution of the two rainfall erosivity parame-
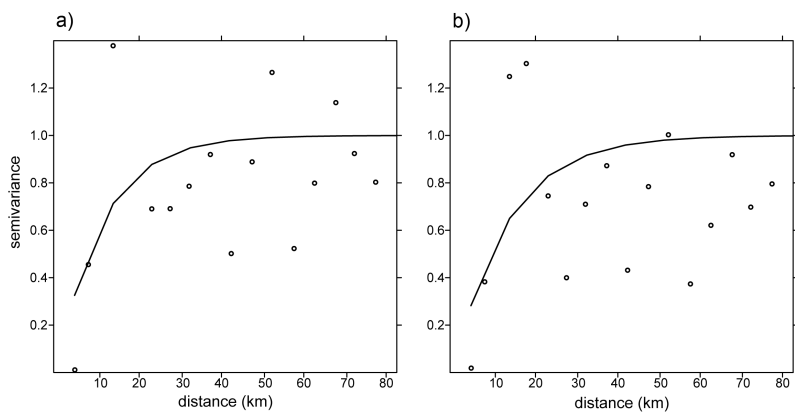

Fig. 2. Empirical semivariograms (circles) and fitted semivariogram Gaussian models (lines) of the rainfall erosivity indices: (A) R factor; (B) $\mathrm{EI}_{30}$ index. Range parameters are: $10.98 \mathrm{~km}$ (R factor) and $13.05 \mathrm{~km}\left(\mathrm{EI}_{30}\right.$ index $)$.

ters (Figs. 3 and 4). Differences between interpolation methods were more evident for the $\mathrm{EI}_{30}$ index than for the $\mathrm{R}$ factor. The $\mathrm{R}$ factor was highest - from 1200 to $4500 \mathrm{MJ} \mathrm{mm} \mathrm{ha}{ }^{-1} \mathrm{~h}^{-1} \mathrm{y}^{-1}$ - in two areas: i) in the Pyrenees Range at the north, especially in the central part; and ii) in the south-east mountainous part, corresponding to the Iberian Range and the southern east region. The lowest values - from 40 to $800 \mathrm{MJ} \mathrm{mm} \mathrm{ha}^{-1} \mathrm{~h}^{-1} \mathrm{y}^{-1}$ - appeared in the north-west of the area and in the centre of the Ebro River valley. The spatial distribution of the $\mathrm{EI}_{30}$ index was slightly different, showing a gradient from the north-west (Cantabric Sea) to the south-east (Mediterranean Sea), modified to a certain extent by the relief. The highest values from 70 to $190 \mathrm{MJ} \mathrm{mm} \mathrm{ha}^{-1} \mathrm{~h}^{-1}$ - were found in the southeast corner, along the coast. Lower values - from 8 to $40 \mathrm{MJ} \mathrm{mm} \mathrm{ha}^{-1} \mathrm{~h}^{-1}$ - are found close to the Cantabric Sea. This pattern is similar to the distribution of the extreme rainfall events in the region (Beguería et al., 2009), and is an indicator of the $\mathrm{EI}_{30}$ index being closely related to the most intense rainfall events.

\subsection{Spatial distribution of the rainfall erosivity indices}

The spatial distribution of both indices over the study area can be explained to a large extent by the proximity to - or isolation from - the water masses (the Cantabrian and Mediterranean seas). The relief, with mountain ranges to the north, south and east of the region, modify this general pattern by increasing rainfall in those areas. Another effect of the relief is the isolation of the central area from the main precipitation sources, i.e. creating a zone of rain shadow.

Despite the general spatial pattern, differences were evident between the models. The maps produced by the local methods - IDW and Spline with tension - were very much influenced by individual observations. In most cases, local variance can be associated with the occurrence of anomalous events or very specific conditions, and might not reflect the general pattern adequately. The maps produced by these two 


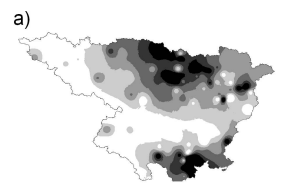

b)

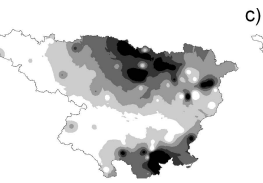

c)

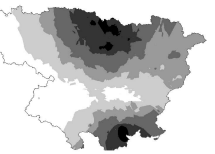

e)

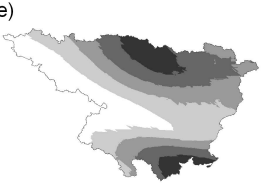

f)

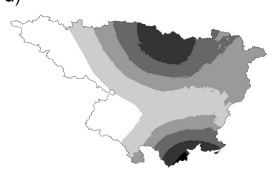

d)

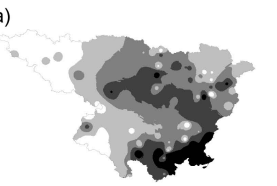

b)

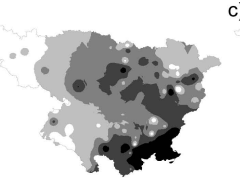

c)

d)

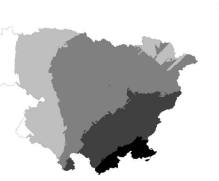

e)

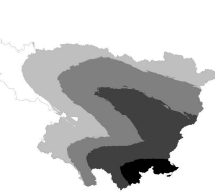

g)

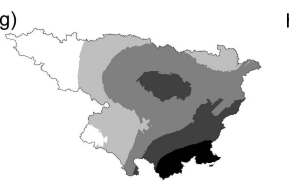

$406008001000120014004500 \mathrm{MJ} \mathrm{mm} \mathrm{ha}^{-1} h^{-1} \mathrm{y}^{-1}$ f)
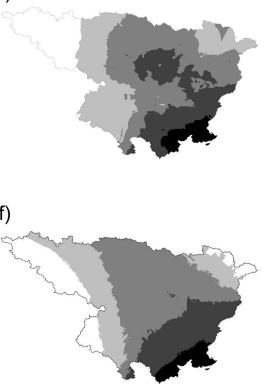

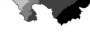
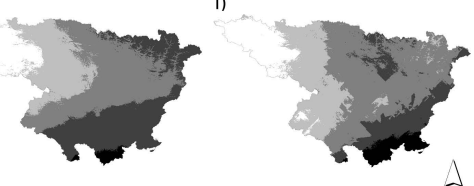

Fig. 3. Rainfall erosivity maps (RUSLE R factor) for the Ebro Basin: (a) inverse distance weighting surface; (b) spline with tension $(\phi=5000)$; (c) smoothing spline $(\phi=400)$; (d) ordinary kriging; (e) ordinary kriging with anisotropy; (f) universal kriging; (g) cokriging; (h) regression model (GLS); (i) regression-kriging.

methods varied slightly depending on the value of the $r$ and $\psi$ parameters (maps not shown), but in all cases they had this characteristic. The smoothed splines method, which includes a smoothing function to reduce excessive influence of local observations, produced a more regularized output.

Geostatistical methods - OK, OK with anisotropy and CK - produced much more smoothed results than the local methods, yet retaining a good degree of detail. Anisotropy modified only slightly the results from OK by orienting the estimated surface in the direction NW-SE. The R factor map resulting from UK - detrending the data by a second order polynomial - was very similar to the surfaces generated by local interpolators, i.e. it showed a high influence of local observations. The result of $\mathrm{CK}-\mathrm{OK}$ with elevation as a covariate - showed only a marginal increase in detail with respect to $\mathrm{OK}$.

The surface generated by GLS regression was similar to the CK surface. The regression models were significant at $\alpha=0.05$, although the coefficient of determination $\left(r^{2}\right)$ of the models was not high $(0.212$ for the $\mathrm{R}$ factor and 0.218 for the $\mathrm{EI}_{30}$ index). The only significant variables at $\alpha=0.05$ were the spatial coordinates, and just for the $\mathrm{R}$ factor, revealing the poor explanatory capacity of other auxiliary variables elevation and solar radiation (Table 2). This was also evident by the low values of the beta coefficients of these two variables.

In the maps obtained by regression-kriging (RK) the influence of the interpolation of the residuals was evident. The predicted map was very similar to the UK surface, especially in the case of the $\mathrm{R}$ factor. In the $\mathrm{EI}_{30}$ index maps the influence of elevation and radiation could be eye noticed.

Fig. 4. Rainfall erosivity maps (average $\mathrm{EI}_{30}$ index of the erosive events) for the Ebro Basin: (a) inverse distance weighting surface; (b) spline with tension $(\phi=5000)$; (c) smoothing spline ( $\phi=400)$; (d) ordinary kriging; (e) ordinary kriging with anisotropy; (f) universal kriging; (g) co-kriging; (h) regression model (GLS); (i) regression kriging.

Table 2. Results of the generalized least squares regression of the $\mathrm{R}$ factor and the $\mathrm{EI}_{30}$ index: regression coefficients, standardized coefficients and significance level for each independent variable.

\begin{tabular}{lrrl}
\hline Variable & $\begin{array}{r}\text { Beta } \\
\text { coeff. }\end{array}$ & $\begin{array}{r}\text { Standardized } \\
\text { beta coeff. }\end{array}$ & $\begin{array}{l}\text { Significance } \\
\text { level }\end{array}$ \\
\hline $\mathrm{R}$ factor & & & \\
longitude & 14.411 & 2.658 & $0.023^{*}$ \\
longitude & -21.803 & -2.582 & 0.219 \\
latitude & -0.010 & -2.380 & $0.041^{*}$ \\
latitude $^{2}$ & 0.003 & 2.744 & 0.191 \\
elevation $^{2}$ & 0.087 & 0.047 & 0.579 \\
solar radiation & -201.853 & -0.031 & 0.732 \\
EI $_{30}$ index & & & \\
longitude $^{\text {longitude }}{ }^{2}$ & 0.255 & 1.132 & 0.304 \\
latitude $_{\text {latitude }}^{2}$ & -0.849 & -2.418 & 0.239 \\
elevation $^{2}$ & -0.0001 & -0.861 & 0.432 \\
solar radiation $^{2}$ & 0.0001 & 2.166 & 0.291 \\
\hline
\end{tabular}

* variable is significant at confidence level $\alpha=0.05$.

\subsection{Validation}

All methods underestimated the standard deviation of the $\mathrm{R}$ factor and the $\mathrm{EI}_{30}$ indices, resulting in relatively poor predictions (Tables 3 and 4). The observed standard deviation was 621.7 for the $\mathrm{R}$ factor, which varied in the range 
Table 3. Accuracy measurements for the R factor models: mean and standard deviation of the observed and predicted values, and cross-validations statistics.

\begin{tabular}{lccrcc}
\hline & \multicolumn{2}{c}{ Validation statistics } & & & \\
& Mean & $\begin{array}{l}\text { Standard } \\
\text { deviation }\end{array}$ & MBE & MAE & $\begin{array}{l}\text { Willmott's } \\
D\end{array}$ \\
\hline Observed & 891.40 & 621.77 & & & \\
Predicted & & & & & \\
Inverse Distance Weighting $(r=1)$ & 896.64 & 292.49 & 5.24 & 355.26 & 0.534 \\
Inverse Distance Weighting $(r=2)$ & 891.75 & 346.59 & 0.350 & 356.33 & 0.577 \\
Inverse Distance Weighting $(r=3)$ & 896.85 & 420.40 & 5.44 & 367.40 & 0.595 \\
Smoothed splines [T $(x, y)=400]$ & 895.86 & 275.70 & 4.45 & 354.99 & 0.521 \\
Splines with tension $(\phi=400)$ & 896.74 & 268.30 & 5.33 & 357.45 & 0.497 \\
Splines with tension $(\phi=5000)$ & 890.21 & 324.54 & -1.19 & 348.27 & 0.573 \\
Ordinary kriging (OK) & 885.37 & 252.11 & -6.03 & 357.76 & 0.491 \\
Ordinary kriging with anisotropy & 890.06 & 244.41 & -1.34 & 356.45 & 0.491 \\
Universal kriging (UK) & 890.60 & 359.08 & -0.806 & 355.79 & 0.584 \\
Co-kriging (OK + elev) & 877.69 & 318.02 & -13.71 & 369.52 & 0.513 \\
Regression (GLS) & 900.53 & 292.64 & 9.13 & 386.31 & 0.468 \\
Regression-Kriging & 910.60 & 292.02 & 19.20 & 385.16 & 0.480 \\
(GLS + residuals kriging) & & & & & \\
\hline
\end{tabular}

40-4500 $\mathrm{MJ} \mathrm{mm} \mathrm{ha}^{-1} \mathrm{~h}^{-1} \mathrm{y}^{-1}$, and 23.8 for $\mathrm{EI}_{30}$, which varied in the range $8-190 \mathrm{MJ} \mathrm{mm} \mathrm{ha}^{-1} \mathrm{~h}^{-1}$. Compared with that, the standard deviation of the estimations ranged between 244.4 and 420.4 for $R$ and 11.6 and 16.2 for $\mathrm{EI}_{30}$. Consequently, all models had relatively large absolute errors, which were higher than $30 \%$ of the mean predicted value for most of them. Similarly, the values of the Willmott's $D$ statistic were low. These facts reflect the high random character of both rainfall erosivity indices. The low performance of the models was mostly due to their inability to predict the highest values, especially those above $2000 \mathrm{MJ} \mathrm{mm} \mathrm{ha}^{-1} \mathrm{~h}^{-1} \mathrm{y}^{-1}$ for $R$ and $100 \mathrm{MJ} \mathrm{mm} \mathrm{ha}^{-1} \mathrm{~h}^{-1}$ for $\mathrm{EI}_{30}$, respectively. This can be clearly seen in the goodness of fit plots (Figs. 5 and 6).

Differences between the models regarding the validation statistics were narrow, but allowed for a comparison. According to the validation statistics the local methods ranked best for both indices, showing highest Willmott's $D$ values, and lowest MBE and MAE. The R factor was best predicted by inverse distance weighting with $r=3$, followed by universal kriging, whereas the $\mathrm{EI}_{30}$ index was best fitted by splines with tension $(\phi=5000)$, followed by IDW with $r=3$. Geostatistical models yielded good results, especially Universal Kriging, equalled by Co-kriging (OK plus elevation) in the case of the $\mathrm{EI}_{30}$ index. The result of including anisotropy in OK was only marginally better. Finally, regression based methods - GLS and RK - yielded the lowest validation statistics.

\subsubsection{Local uncertainty}

The previous results evidenced the high level of uncertainty of the predictions of both erosivity indices. The uncertainty model, however, is also a spatial variable and can have strong differences between regions in the study area. The results of Gaussian geostatistical simulation (GGS) helped assessing spatial differences in the uncertainty model (Fig. 7). From
Table 4. Accuracy measurements for the $\mathrm{EI}_{30}$ index models: mean and standard deviation of the observed and predicted values, and cross-validations statistics.

\begin{tabular}{lrlrll}
\hline & \multicolumn{3}{c}{ Validation statistics } \\
& Mean & $\begin{array}{c}\text { Standard } \\
\text { deviation }\end{array}$ & MBE & MAE & $\begin{array}{l}\text { Willmott's } \\
D\end{array}$ \\
& & & & & \\
\hline Observed & 44.32 & 25.85 & & & \\
Predicted & & & & & \\
Inverse Distance Weighting $(r=1)$ & 44.23 & 12.17 & -0.536 & 14.60 & 0.565 \\
Inverse Distance Weighting $(r=2)$ & 43.69 & 13.40 & -0.635 & 14.62 & 0.582 \\
Inverse Distance Weighting $(r=3)$ & 43.82 & 16.22 & -0.502 & 15.17 & 0.584 \\
Smoothed splines $[T(x, y)=400]$ & 44.44 & 12.05 & 0.116 & 14.58 & 0.568 \\
Splines with tension $(\phi=400)$ & 44.48 & 11.68 & 0.156 & 14.62 & 0.553 \\
Splines with tension $(\phi=5000)$ & 44.11 & 13.40 & -0.210 & 14.28 & 0.602 \\
Ordinary kriging (OK) & 44.18 & 11.57 & -0.144 & 14.90 & 0.540 \\
Ordinary kriging with anisotropy & 44.23 & 11.60 & -0.091 & 14.33 & 0.562 \\
Universal kriging (UK) & 43.93 & 13.38 & -0.392 & 15.17 & 0.573 \\
Co-kriging (OK + elev) & 43.97 & 13.41 & -0.357 & 15.18 & 0.573 \\
Regression (GLS) & 44.74 & 12.54 & 0.420 & 16.69 & 0.504 \\
Regression-Kriging & 45.18 & 12.51 & 0.853 & 16.62 & 0.515 \\
(GLS + residuals kriging) & & & & & \\
\hline
\end{tabular}
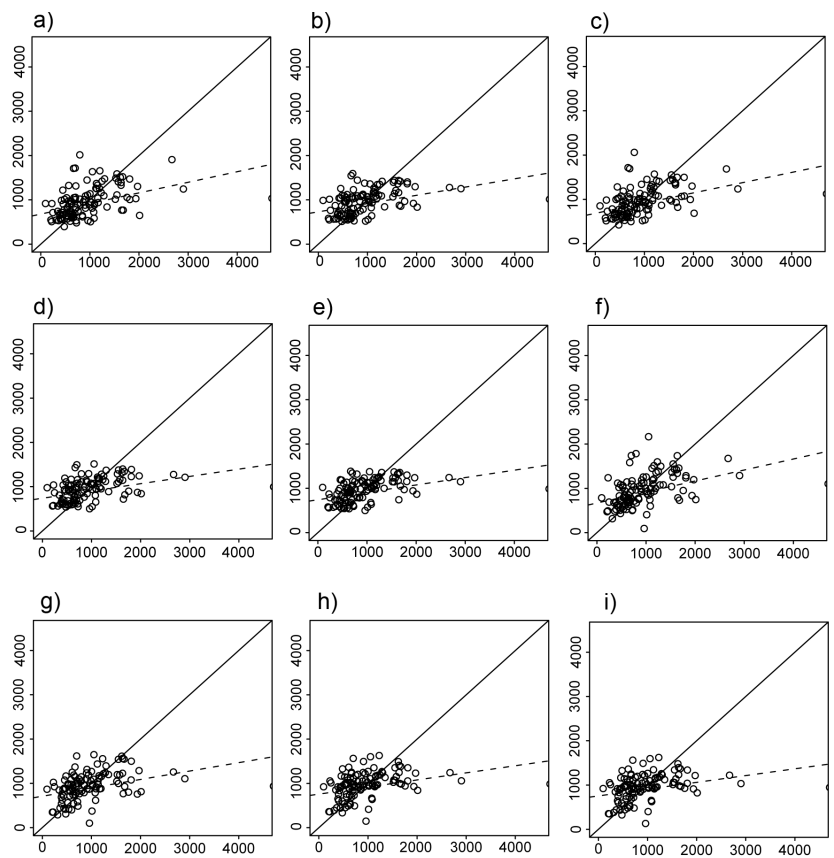

Fig. 5. Comparison between observed (ordinate axis) and predicted (abscissa axis) values for the interpolation methods used for the spatial distribution of the $\mathrm{R}$ factor, line of perfect fit (continuous) and regression line (dashed). (a) inverse distance weighting $(r=2)$; (b) smoothing spline $(\phi=400)$; (c) splines with tension $(\phi=5000)$; (d) ordinary kriging; (e) ordinary kriging with anisotropy; (f) universal kriging; (g) co-kriging; (h) regression model (GLS); (i) regressionkriging.

1000 equiprobable conditional simulations, mean and standard deviation surfaces were generated for the $\mathrm{R}$ factor and the $\mathrm{EI}_{30}$ index. Both surfaces showed the general pattern of their respective rainfall erosivity indices. Local uncertainty was quite high as showed by the standard error maps, where 

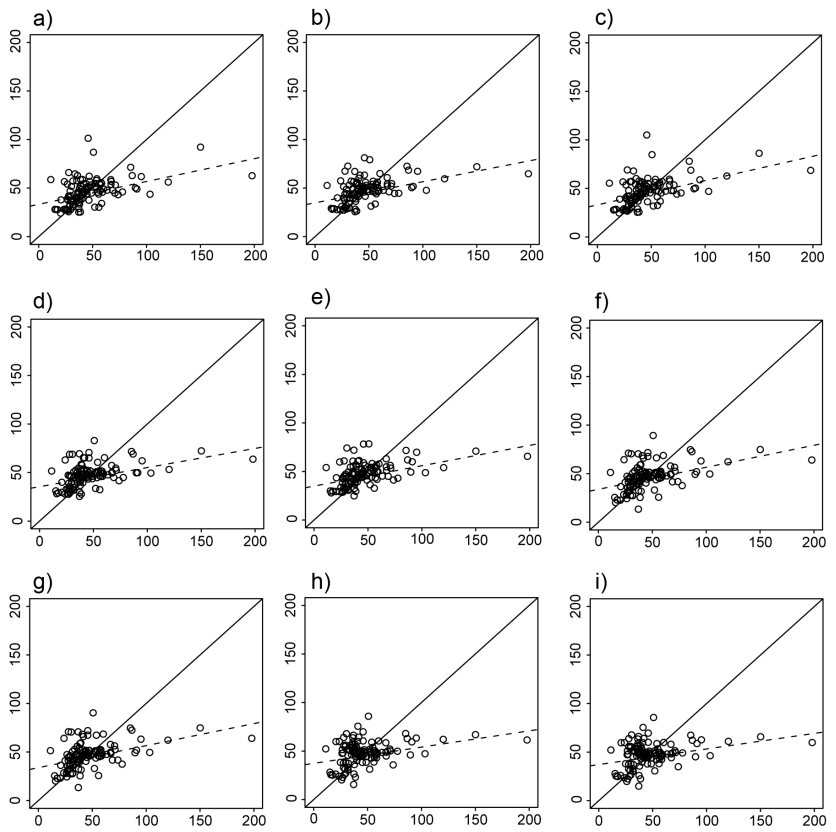

Fig. 6. Comparison between observed (ordinate axis) and predicted (abscissa axis) values for the different interpolation methods used for the spatial distribution of the $\mathrm{EI}_{30}$ index, line of perfect fit (continuous) and regression line (dashed). (a) inverse distance weighting $(r=2)$; (b) smoothing spline $(\phi=400)$; (c) splines with tension $(\phi=5000)$; (d) ordinary kriging; (e) ordinary kriging with anisotropy; (f) universal kriging; (g) co-kriging; (h) regression model (GLS); (i) regression-kriging.

the magnitude of the error ranged between 10 and $100 \%$ of the mean value. The standard error increased rapidly for regions located more than $\sim 15 \mathrm{~km}$ away from any observatory, indicating that the range of the spatial influence of the observations was quite small. This was already suggested by the preliminary analysis of the semivariogram. From that distance, which was larger for the $\mathrm{EI}_{30}$ index than for the $\mathrm{R}$ factor, uncertainty distributed randomly.

\section{Discussion and conclusions}

Rainfall erosivity is an indicator of the precipitation aggressiveness, and depends on the rainfall energy (raindrop size distribution and kinetic energy) and the intensity of the storm event. Rainfall under Mediterranean climate is characterized by high temporal variability and a flashy character. This last characteristic affects especially the rainfall erosivity, which depends on the occurrence of few, very intense, events (González-Hidalgo et al., 2007).

In this study we used the RUSLE R factor and the average $\mathrm{EI}_{30}$ index of the erosive events to assess the spatial distribution of rainfall erosivity on the northeast sector of the Iberian Peninsula. Both variables are characterized by a high temporal variability, especially in the Mediterranean area and a)

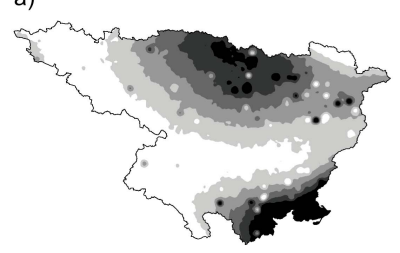

406008001000120014004500

c)

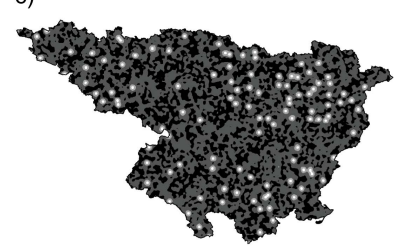

25300500550595

MJ mm ha- $a^{-1} h^{-1}$ b)

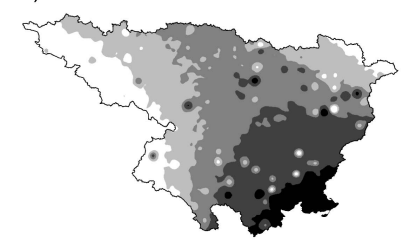

$30 \quad 405070190$

d)

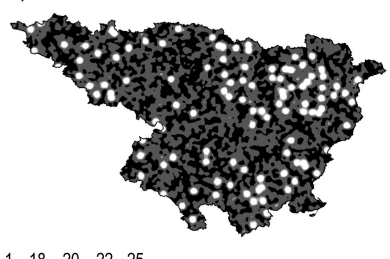

\begin{tabular}{lllll}
1 & 18 & 20 & 22 & 25 \\
\hline
\end{tabular}

Fig. 7. Local uncertainty modeled by Gaussian geostatistical simulation (GGS) for the $\mathrm{R}$ factor and the $\mathrm{EI}_{30}$ index: (a) mean of $\mathrm{R}$ factor; (b) mean of $\mathrm{EI}_{30}$ index; (c) standard error of $\mathrm{R}$ factor; (d) standard error of $\mathrm{EI}_{30}$ index.

in geographically complex regions (Leek and Olsen, 2000; González-Hidalgo et al., 2007). During the initial stage of the analysis it was evident that close observatories could have very different values of $R$ and $\mathrm{EI}_{30}$, and this was confirmed by the analysis of the semivariogram.

Comparing both erosivity indices, the average $\mathrm{EI}_{30}$ index of the erosive events had larger variability than $R$, being more affected by the most extreme events. The spatial pattern of $\mathrm{EI}_{30}$ showed a clear northwest-southeast gradient. The highest values were found in the southern region, coinciding with the distribution of the peak intensity of extreme rainfall events for the same area (Beguería et al., 2009). The spatial distribution of the $\mathrm{R}$ factor showed the highest values in the north and the south-east part, isolating the centre of the valley with low values. Previous works have analyzed the spatial distribution of the USLE R factor in Spain (ICONA, 1988). The value range and the spatial distribution are similar to the results of our study. There are differences however in the south-east corner along the Mediterranean coastland. The map of ICONA (1988) did not show the high erosivity values which were presented in our dataset. This discrepancy could be due to the different period of analysis, since the study of ICONA (1988) was based on data from the period 1966-1976, although this issue could not be assessed using the current dataset. Unfortunately, the technical brief attached to the map of ICONA did not report enough details allowing for a deeper comparison. The $\mathrm{R}$ factor values found for the area are similar to the ones published by other authors for the Mediterranean region: 697.4 to $3741.8 \mathrm{MJ} \mathrm{mm} \mathrm{ha}^{-1} \mathrm{~h}^{-1} \mathrm{y}^{-1}$ in Portugal (De Santos Loureiro and De Azevedo Coutinho, 2001); 471 and $3214 \mathrm{MJ} \mathrm{mm} \mathrm{ha}^{-1} \mathrm{~h}^{-1} \mathrm{y}^{-1}$ in Italy (Diodato, 2004); 339 to 
$818 \mathrm{MJ} \mathrm{mm} \mathrm{ha}{ }^{-1} \mathrm{~h}^{-1} \mathrm{y}^{-1}$ in Central Spain (Boellstorff and Benito, 2005); or 419.01 to $1124.36 \mathrm{MJ} \mathrm{mm} \mathrm{ha}^{-1} \mathrm{~h}^{-1} \mathrm{y}^{-1}$ in Sicily (Onori et al., 2006). We are not aware of previous studies analyzing the spatial distribution of the average $\mathrm{EI}_{30}$ index.

Despite the high spatial variability of both indices, the mapping methods tested were able to capture the main spatial pattern of rainfall erosivity in the area. The spatial distribution can be explained by seasonal atmospheric behaviour which causes the major stormy events. In the Pyrenees these events are related with south-western flows confronting the mountains triggering orographic rainfall in winter, and convective storms in summer. Close to the Mediterranean Sea the heating contrast between the atmosphere upper levels and continental and maritime surfaces, more intense during fall, generates intense storms. This is the principal cause of heavy rainfalls in the southeastern area (Llasat and Puigcerver, 1997). These synoptic situations explain the spatial pattern of rainfall erosivity, which is linked to the most extreme events of the year. In addition, the strong relief adds complexity to the climate dynamics making more complex to obtain reliable models. It is responsible of orographic precipitation increase, and it also generates temperature differences in narrow spaces which contribute to the formation of convective cellules and local storms. Thus, the general pattern present in all rainfall erosivity maps show a clear north-west to south-east gradient, and marked local differences caused by the relief.

The comparison of several interpolation techniques yielded mixed results, since no single method arouse as optimal according to all validation metrics, and the differences between models were narrow. Local interpolation methods yielded the best results overall, which can be explained by the very high spatial variability of rainfall erosivity as found in the preliminary semivariogram analysis. However, the maps produced by these methods masked the global pattern by introducing spatial noise due to the excessive weight given to local observations. Geostatistical methods were able to capture more general pattern ranking slightly lower from the local methods in the validation statistics. Among them, universal kriging (UK) ranked best and was able to capture local detail whereas conserving also the general pattern. Regression-based methods (GLS regression and regressionkriging) ranked lowest due to their most global character. Besides, the independent variables selected - elevation and solar radiation - did not have significant explanatory capacity. Regression-kriging ranked slightly better than regressionbased methods, but their prediction was not better than that of UK.

The results obtained in the present study reflected the highly random character of rainfall erosivity, evaluated by both indices - the $\mathrm{R}$ factor and $\mathrm{EI}_{30}$ index. In general, the models were bad at predicting the highest values of both indices, due to the presence of outlier observations. The uncertainty of the predicted values can be explained by the natural climate variability in the study area, and also by the length of the analysis period. Other authors have reported high variability of soil erosion values in the Mediterranean region, both in space and time (González-Hidalgo et al., 2007). Though, more information is needed for the assessment of the causal factors responsible of the high uncertainty present in all models. The quantification of uncertainty by means of Gaussian geostatistical simulation (GGS), expressed by standard error surfaces, allowed estimating confidence bands for the prediction surfaces. These cartographies constituted an important result for the applicability of the rainfall erosivity maps.

The results suggest that the database needs to be improved both in time (longer high-frequency precipitation series) and space (denser network). With respect to the length of the data series, it is generally accepted that a minimum of 20 years is desirable for rainfall erosivity analysis (Renard and Freimund, 1994; Renard et al., 1997; Curse et al., 2006; Verstraeten et al., 2006). Unfortunately, there are very few data bases of high time resolution rainfall records and a good spatial coverage, as the one used in this work. Longer series are needed for reducing the strong influence of outlier observations. With respect to the spatial distribution of the data sets, the results showed spatial autocorrelation limited to a perimeter of $\sim 15 \mathrm{~km}$. This fact evidenced the need for improving the spatial coverage if better predictions are to be achieved.

The availability of high-quality environmental maps is a key issue for agricultural and hydrological management in many regions of the World. Rainfall erosivity maps can be of high relevance as a guidance for soil conservation practices, and also because they are usually part of erosion models such as the RUSLE. Recently, the RUSLE model has been implemented into GIS packages, integrating all the factors as different layers. Hence, the accuracy of the spatial surface of each factor is propagated to the outputs of the model. Compared to other climatic variables, rainfall erosivity is characterized by a high spatial and inter-annual variability, what makes mapping more difficult.

Further research may be directed to find reliable erosivity indices which can be computed from daily precipitation data. This would allow using daily precipitation data bases, which are usually longer and have a higher spatial coverage. This would lead to more robust results, and will also make trend analysis possible.

Acknowledgements. We want to express our gratitude to the Ebro River Hydrographical Confederation (Confederación Hidrográfica del Ebro - CHE) for providing the data used on this study. This work has been supported by the research projects CGL200800831/BTE, CGL2005-04508/BOS and CGL2008-01189/BTE, funded by the Spanish Ministry of Science and Innovation. Research of M. A. is supported by a JAE-Predoc Research Grant from the Spanish National Research Council (Consejo Superior de Investigaciones Científicas - CSIC). 
Edited by: A. Bronstert

\section{References}

Ahmed, S. and De Marsily, G.: Comparison of geostatistical methods for estimating transmissivity using data on transmissivity and specific capacity, Water Resour. Res., 23, 1717-1737, 1987.

Arnoldus, H. M. J.: Methodology used to determine the maximum potential average annual soil loss due to sheet and rill erosion in Morocco, FAO Soils Bulletin, 34, 39-51, 1977.

Beguería, S. and Vicente-Serrano, S. M.: Mapping the hazard of extreme rainfall by peaks over threshold extreme value analysis and spatial regression techniques, J. Appl. Meteorol., 45, 108124, 2006.

Beguería, S., Vicente-Serrano, S. M., López-Moreno, J. I., and García-Ruiz, J. M.: Annual and seasonal mapping of peak intensity, magnitude and duration of extreme precipitation events across a climatic gradient, North-east Iberian Peninsula, Int. J. Climatol., 29(12), 1759-1779, doi:10.1002/joc.1808, 2009.

Beguería, S. and Pueyo, Y.: A comparison of simultaneous autoregressive and generalized least squares models for dealing with spatial autocorrelation, Global Ecol. Biogeogr., 18(3), 273-279, 2009.

Boellstorff, D. and Benito, G.: Impacts of set-aside policy on the risk of soil erosion in central Spain, Agr. Ecosyst. Environ., 107, 231-243, 2005.

Borrough, P. A. and McDonnell, R. A.: Principles of geographical information systems, Oxford University Press, 1998.

Brown, D. P. and Comrie, A. C.: Spatial modelling of winter temperature and precipitation in Arizona and New Mexico, USA, Climate Res., 22, 115-128, 2002.

Brown, L. C. and Foster, G. R.: Storm erosivity using idealized intensity distributions, T. ASAE, 30, 379-386, 1987.

Casas, M. C., Herrero, M., Ninyerola, M., Pons, X., Rodríguez, R., Rius, A., and Redaño, A.: Analysis and objective mapping of extreme daily rainfall in Catalonia, Int. J. Climatol., 27, 399-409, 2007.

Chiles, J. and Delfiner, P.: Geostatistics: modelling spatial uncertainty, Wiley, New York, 1999.

Cressie, N. A. C.: Statistics for spatial data, rev. edn., John Wiley and Sons, 1993.

Creus, J.: Las sequías en el valle del Ebro, in: Causas y consecuencias de las sequías en España, edited by: Gil, A. and Morales, A., Universidad D' Alacant, 231-259, 2001.

Cuadrat, J. M.: Las sequías en el valle del Ebro. Aspectos climáticos y consecuencias económicas, Rev. Real Acad. Ciencias, 85, 537$545,1991$.

Curse, R., Flanagan, J., Frankenberger, B., Gelder, D., Herzmann, D., James, D., Krajenski, W., Kraszewski, M., Laflen, J., Opsomer, J., and Todey, D.: Daily estimates of rainfall, water runoff and soil erosion in Iowa, J. Soil Water Conserv., 61, 191-199, 2006.

Daly, C., Gibson, W. P., Taylor, G. H., Johnson, G. L., and Pasteris, P.: A knowledge-based approach to the statistical mapping of climate, Climate Res., 22, 99-113, 2002.

Deutsch, C. V. and Journel, A. G.: Gslib: Geostatistical software library and user's guide, Oxford university press, 1998.

Diggle, P. J., Ribero, P. J., an dCristensen, O. F.: An introduction to model basis geostatistics, in: Spatial statistics and computa- tional methods. Lecture notes in statistics, edited by: Møller, J., Springer-Verlag, New York, 2002.

Diodato, N.: Estimating RUSLEs rainfall factor in the part of Italy with a Mediterranean rainfall regime, Hydrol. Earth Syst. Sci., 8, 103-107, 2004, http://www.hydrol-earth-syst-sci.net/8/103/2004/.

Dirks, K. N., Hay, J. E., Stow, C. D., and Harris D.: High-resolution studies of rainfall on Norfolk Island. Part II: Interpolation of rainfall data, J. Hydrol., 208, 187-193, 1998.

Domínguez-Romero, L., Ayuso Muñoz, J. L., and García Marín, A. P.: Annual distribution of rainfall erosivity in western Andalusia, southern Spain, J. Soil Water Conserv., 62, 390-401, 2007.

Dunkerley, D.: Rain event properties in nature and in rainfall simulation experiments: a comparative review with recommendations for increasingly systematic study and reporting, Hydrol. Process., 22(22), 4415-4435, doi:10.1002/hyp.7045, 2008.

Efron, B. and Tibshirani, R. J.: Improvements on cross-validation: the .632+ bootstrap method, J. Am. Stat. Assoc., 92, 548-560, 1997.

García-Ruiz, J. M., Arnáez, J., White, S. M., Lorente, A., and Beguería, S.: Uncertainty assessment in the predition of extreme rainfall events: an example from the Central Spanish Pyrenees, Hydrol. Process., 14, 887-898, 2000.

Garrido, J. and García, J. A.: Periodic signals in Spanish monthly precipitation data, Theor. Appl. Climatol., 45, 97-106, 1992.

Gobin, A., Jones, R., Kirkby, M., Campling, P., Govers, G., Kosmas, C., and Gentile, A. R.: Indicators for pan-European assessment and monitoring of soil erosion by water, Environ. Sci. Policy, 7, 25-38, 2004.

González-Hidalgo, J. C., Peña-Monnè, J. L., and de Luis, M.: A review of daily soil erosion in western Mediterranean areas, Catena, 71, 193-199, 2007.

Goodale, C. L., Aber, J. D., and Ollinger, S. V.: Mapping monthly precipitation, temperature and solar radiation from Ireland with polynomial regression and a digital elevation model, Climate Res., 10, 35-49, 1998.

Goovaerts, P.: Geostatistics for natural resources evaluation, Oxford University Press, New York, 1997.

Goovaerts, P.: Using elevation to aid the geostatistical mapping of rainfall erosivity, Catena, 34, 227-242, 1999.

Goovaerts, P.: Geostatistical modelling of uncertainty in soil science, Geoderma, 103, 3-26, 2001.

Hengl, T., Heuvelink, G. B. M., and Stain, A.: A gereric framework for spatial prediction of soil variables based on regressionkriging, Geoderma, 120, 75-93, 2004.

Hoyos, N., Waylen, P. R., and Jaramillo, A.: Seasonal and spatial patterns of erosivity in a tropical watershed of the Colombian Andes, J. Hydrol., 314, 177-191, 2005.

Hudson, N.: Soil Conservation, Cornell University Press, Ithaca, 1971.

Kinnell, P. I. A. and Risse, L. M.: USLE-M: Empirical modelling rainfall erosion through runoff and sediment concentration, Soil Sci. Soc. Am. J., 62, 1667-1672, 1998.

ICONA: Agresividad de la lluvia en España. Valores del factor R de la Ecuación Universal de Pérdida de Suelo, Ministerio de Agricultura, pesca y alimentación, España, 1988.

Isaaks, E. H. and Strivastava, R. M.: An introduction to applied geostatistics, Oxford University Press, Oxford, 1989.

Lal, R.: Soil erosion on alfisols in Western Nigeria. III - Effects of 
rainfall characteristics, Geoderma, 16, 389-401, 1976.

Lana, X. and Burgueño, A.: Spatial and temporal characterization of annual extreme droughts in catalonia (Northeast Spain), Int. J. Climatol., 18, 93-110, 1998.

Lasanta, T.: Gestión agrícola y erosión del suelo en la cuenca del Ebro: el estado de la cuestión, Zubía, 21, 76-96, 2003.

Llasat, M. C. and Puigcerver, M.: Meteorological factors associated with floods in the north-eastern part of the Iberian Peninsula, Nat. Hazards, 5, 133-151, 1994.

Llasat, M. C.: An objective classification of rainfall events on the basis of their convective features: Application to rainfall intensity in the northeast of Spain, Int. J. Climatol., 21, 1385-1400, 2001

Leek, R. and Olsen, P.: Modelling climatic erosivity as a factor for soil erosion in Denmark: changes and temporal trends, Soil Use Manage., 16, 61-65, 2000.

Lim, K. J., Sagong, M., Engel, B. A., Tang, Z., Choi, J., and Kim, K.: GIS-based sediment assessment tool, Catena, 64, 61-80, 2005.

López-Vicente, M., Navas, A., and Machín, J.: Identifying erosive periods by using RUSLE factors in mountain fields of the Central Spanish Pyrenees, Hydrol. Earth Syst. Sci., 12, 523-535, 2008, http://www.hydrol-earth-syst-sci.net/12/523/2008/.

Martín-Vide, J.: Diez características de la pluviometría española decisivas en el control de la demanda y el uso del agua, Boletín de la AGE, 18, 9-16, 1994.

McBratney, A. B. and Webster, R.: Chosing functions for semivariograms of soil properties and fitting them to sampling estimates, J. Soil Sci., 37(4), 617-639, 1986.

McBratney, A., Mendoça-Santos, M., and Minasny, B.: On digital soil mapping, Geoderma, 117, 3-52, 2003.

Millward, A. A. and Mersey, J. E.: Adapting the RUSLE to model soil erosion potential in a mountainous tropical watershed, Catena, 38, 109-129, 1999.

Mitasova, H., Mitas, L., Brown, W. M., Gerdes, D. P., Kosinovsky, I., and Baker, T.: Modelling spatially and temporally distributed phenomena: new methods and tools for GRASS GIS, Int. J. Geogr. Inf. Syst., 9, 433-446, 1995.

Mutua, B. M., Klik, A., and Loiskandl, W.: Modeling soil erosion and sediment yield at a catchment scale: the case of masinga catchment, Kenya, Land Degrad. Dev., 17, 557-570, 2006.

Ninyerola, M., Pons, X., and Roure, J. M.: A methodological approach of climatological modelling of air temperature and precipitation through GIS techniques, Int. J. Climatol., 20, 1823 1841,2000

Ninyerola, M., Pons, X., and Roure, J. M.: Monthly precipitation mapping of the Iberian Peninsula using spatial interpolation tools implemented in a Geographic Information System, Theor. Appl. Climatol., 89, 195-209, 2007.

Ninyerola, M., Pons, X., and Roure, J. M.: Objective air temperature mapping for the Iberian Peninsula using spatial interpolation and GIS, Int. J. Climatol., 27, 1231-1242, 2007.

Odeh, I. O. A., McBratney, A. B., and Chittleborough, D. J.: Spatial prediction of soil properties from landform attributes derived from a digital elevation model, Geoderma, 63, 197-214, 1994.

Odeh, I. O. A., McBratney, A. B., and Chittleborough, D. J.: Further results on prediction of soil properties from terrain attributes: heterotopic cokriging and regression-kriging, Geoderma, 67(34), 215-226, 1995
Onori, F., De Bonis, P., and Grauso, S.: Soil erosion prediction at the basin scale using the revised universal soil loss equation (RUSLE) in a catchment of Sicily (southern Italy), Environ. Geol., 50(8), 1129-1140, doi:10.1007/S00254-006-0286-1, 2006.

Peñarrocha, D., Estrela, M. J., and Millán, M.: Classification of daily rainfall patterns in a Mediterranean area with extreme intensity levels: the Valencia region, Int. J. Climatol., 22, 677-695, 2002.

Pons, X.: Manual of miramon, Geographic Information System and Remote Sensing Software, Centre de Recerca Ecològica i Aplicacions Forestals (CREAF): Bellaterra, available at: http: //www.creaf.uab.es/miramon, 2006.

Pons, X. and Ninyerola, M.: Mapping a topographic global solar radiation model implemented in a GIS and calibrated with ground data, Int. J. Climatol., 28(13), 1821-1834, doi:10.1002/joc.1676, 2008.

Prudhome, C. and Reed, D. W.: Mapping extreme rainfall in a mountainous region using geostatistical techniques: A case study in Scotland, Int. J. Climatol., 19, 1337-1356, 1999.

R Development Core Team: $R$ : A Language and Environment for Statistical Computing, Vienna (Austria), R Foundation for Statistical Computing, 2008.

Renard, K. G. and Freimund, J. R.: Using monthly precipitation data to estimate the $R$ factor in the revised USLE, J. Hydrol., 157, 287-306, 1994.

Renard, K. G., Foster, G. R., Weesies, G. A., McCool, D. K., and Yoder, D. C.: Predicting Soil Erosion by Water: A Guide to Conservation Planning with the Revised Universal Soil Loss Equation (RUSLE), Handbook \#703, US Department of Agriculture, Washington, DC, 1997.

Romero, R., Guijarro, J. A., Ramis, C., and Alonso, S.: A 30-year (1964-1993) daily rainfall data base for the Spanish Mediterranean regions: first exploratory study, Int. J. Climatol., 18, 541560, 1998.

De Santos Loureiro, N. and De Azevedo Coutinho, M.: A new procedure to estimate the RUSLE $\mathrm{EI}_{30}$ index, based on monthly rainfall data and applied to the Algarve region, Portugal, J. Hydrol., 250, 12-18, doi:10.1016/S0022-1694(01)00387-0, 2001.

Shi, Z. H., Cai, C. F., Ding, S. W., Wang, T. W., and Chow, T. L.: Soil conservation planning at the small watershed level using RUSLE with GIS, Catena, 55, 33-48, 2004.

Tobler, W. R.: A computer movie simulating urban growth in Detroit region, Econ. Geogr., 46, 234-240, 1970.

Verstraeten, G., Poesen, J., Demarée, G., and Salles, C.: Long-term (105 years) variability in rain erosivity as derived from 10-min rainfall depth data for Ukkel (Brussels, Belgium): implications for assessing soil erosion rates, J. Geophys. Res., 111, D22109, doi:10.1029/2006JD007169, 2006.

Vicente-Serrano, S. M., Saz-Sánchez, M. A., and Cuadrat, J. S. Comparative analysis of interpolation methods in the middle Ebro Valley (Spain): application to annual precipitation and temperature, Climate Res., 24, 161-180, 2003.

Vicente-Serrano, S. M.: Las sequías climáticas en el valle medio del Ebro: factores atmosféricos, evolución temporal y variabilidad espacial, Publicaciones del Consejo de Protección de la Naturaleza de Aragón, 2005.

Vicente-Serrano, S. M., Lanjeri, S., and López-Moreno, J. I.: Comparison of different procedures to map reference evapotranspi- 
ration using geographical information systems and regressionbased techniques, Int. J. Climatol., 27, 1103-1118, 2007.

Vogt, J. V., Viau, A. A., and Paquet, F.: Mapping regional air temperature fields using satellite derived surface skin temperatures, Int. J. Climatol., 17, 1559-1579, 1997.

Wackernagel, H.: Multivariate Geostatistics: an introduction with applications, Springer, Berlin/London, XIV, 1998.

Weisse, A. K. and Bois, P.: A comparison of methods for mapping statistical characteristics of heavy rainfall in the French Alps: The use of daily information, Hydrolog. Sci. J., 47, 739-752, 2002.

Weiss, S. M. and Kulikowski, C. A.: Computer Systems That Learn, Morgan Kaufmann, 1991.

Willmott, C. J.: On the validation of models, Phys. Geogr., 2, 184194, 1981.
Willmott, C. J. and Matsuura, K.: Advantages of the mean absolute error (MAE) over the root mean square error (RMSE) in assessing average model performance, Climate Res., 30, 79-82, 2005.

Winchell, M. F., Jackson, S. H., Wadley, A. M., and Srinivasan, R.: Extension and validation of a geographic information systembased method for calculating the Revised Universal Soil Loss Equation length-slope factor for erosion risk assessments in large watersheds, J. Soil Water Conserv., 63, 105-111, 2008.

Wischmeier, W. H.: A rainfall erosion index for a universal soil-loss equation, Soil Sci. Soc. Am. Pro., 23, 246-249, 1959.

Wischmeier, W. H. and Smith, D. D.: Predicting rainfall erosion losses: a guide to conservation planning, USDA Handbook 537, Washington, DC, 1978. 